EXTENDED REPORT

\title{
Infective keratitis in older patients: a 4 year review, 1998-2002
}

\author{
T K H Butler, N A Spencer, C C K Chan, J Singh Gilhotra, K McClellan
}

Br J Ophthalmol 2005;89:591-596. doi: 10.1136/bjo.2004.049072

See end of article for authors' affiliations

.....................

Correspondence to: Dr K McClellan,

Department of Clinical Ophthalmology and Save Sight Institute, University of Sydney, GPO Box 4337, Sydney, NSW, 2001 Australia; kathy@eye. usyd.edu.au

Accepted for publication 1 September 2004

\begin{abstract}
Background/aim: There are few clinical series in the literature of infective keratitis in the elderly, even though this age group constitutes a significant proportion of those affected by this condition. The authors aimed to determine the incidence and risk factors for infective keratitis in those over 60 years, the causative organisms, antibiotic susceptibilities, visual and tectonic outcome, and surgical intervention rate. Methods: A retrospective review of all patients aged 60 years and over admitted to the Sydney Eye Hospital with a diagnosis of infective keratitis, between September 1998 and December 2002. Results: 190 patients were identified with a mean age of 75.5 (SD 9.6) years (range 60-101). Local risk factors were found in $93.7 \%$, and systemic risk factors in $27.9 \%$. Organisms were cultured in $62.8 \%$, and $7.9 \%$ had positive herpes simplex virus (HSV) polymerase chain reaction (PCR). Perforation or severe thinning occurred in $36 \%$ overall, but in $80 \%$ with positive HSV PCR. Acute surgical intervention was required in $43.7 \%$, with acute penetrating keratoplasty performed in $17.9 \%$, and $8.9 \%$ required evisceration. Mean presenting visual acuity was 1.82 (SD 1.24), equivalent to $6 / 300$, excluding $26.3 \%$ with vision of light perception (LP) or worse. Mean final visual acuity was 1.24 (SD 1.16), equivalent to 6/ 100 , excluding $19.5 \%$ with vision of LP or worse $(p<0.0005)$.

Conclusions: The elderly represent a distinct clinical group in the context of microbial keratitis. Predisposing factors are very common, they present with poor vision, have a high complication and surgical intervention rate, and a poor visual outcome compared to younger patients. The microbiological spectrum is similar to younger age groups, except that HSV is more common and may increase the risk of severe corneal thinning and perforation. Most bacterial isolates remain sensitive to currently available antibiotic preparations.
\end{abstract}

p nfective keratitis is a significant cause of blindness and preventable ocular morbidity worldwide. There are many published series of infective keratitis from both temperate and tropical parts of the world, and management strategies are well established. However, infective keratitis continues to be an important cause of hospital admission, particularly among vulnerable patient groups such as the elderly. With increasing numbers of those of retirement age, the demands this group place on healthcare systems worldwide will continue to rise. Despite this, there are only two published studies of infective keratitis in the elderly population: the first from the United States, ${ }^{1}$ a series from over 20 years ago, and more recently, one from rural southern India. ${ }^{2}$

The elderly represent a distinct clinical group in the context of microbial keratitis, as they are less likely to be contact lens wearers (except in aphakia) than younger patients, they are more likely to have had previous or co-existent ocular disease or surgery, and the visual prognosis is significantly worse in older patients. ${ }^{2}{ }^{3}$ Musch et $a l^{4}$ showed a bimodal age distribution for infective keratitis with two distinct peaks of incidence, one around the age of 30, and another at 70 years.

The purpose of this study was to identify in those over 60 years, the risk factors for infective keratitis, the microbiological spectrum, and the visual and tectonic outcome, over a 4 year period at a single tertiary referral centre in south eastern Australia.

\section{PATIENTS AND METHODS}

All patients aged 60 years and over who were admitted to the Sydney Eye Hospital between September 1998 and December 2002 with a diagnosis of infective keratitis were included in the study. Cases were identified from the database of clinical codes, based on the primary and other diagnoses, recorded for each patient on discharge from the hospital.

Medical records were then retrieved and the data recorded on a standardised form. The data set included details of patients' age, sex, length of hospital admission, treatment before admission, identifiable local and systemic risk factors, pre-existing ocular disease, other medical history, clinical features, investigations performed, organisms identified, antibiotic sensitivities, treatment and duration of treatment, complications, acute and other surgical interventions, final diagnosis, presenting and final visual acuity, and length of follow up.

Visual acuity was documented in Snellen format, and converted into logMAR equivalent values for analysis. Presenting and final visual acuities were compared using two tailed, paired Student's $t$ test. Those with visual acuity of light perception (LP) or worse were excluded from mean calculations, but stated separately, as these levels of visual acuity cannot be assigned geometric mean values. ${ }^{5}$

Corneal scrapes were routinely performed on admission with a flame sterilised Kimura spatula or a sterile scalpel blade, placing the specimen onto slides for Gram stain, and direct inoculation of culture media: horse blood agar for aerobic and anaerobic culture, chocolate agar, cooked meat broth, and Sabouraud's dextrose agar for fungi. If Acanthamoeba was suspected, non-nutrient agar seeded with Escherichia coli was also inoculated. In addition, if clinically indicated, patients were tested for herpes simplex virus

Abbreviations: CVA, cerebrovascular accident; DFA, direct fluorescent antibody; HSV, herpes simplex virus; $\mathrm{HZO}$, herpes zoster ophthalmicus; $\mathrm{LP}$, light perception; MIC, minimum inhibitory concentration; PCR, polymerase chain reaction; PK, penetrating keratoplasty 


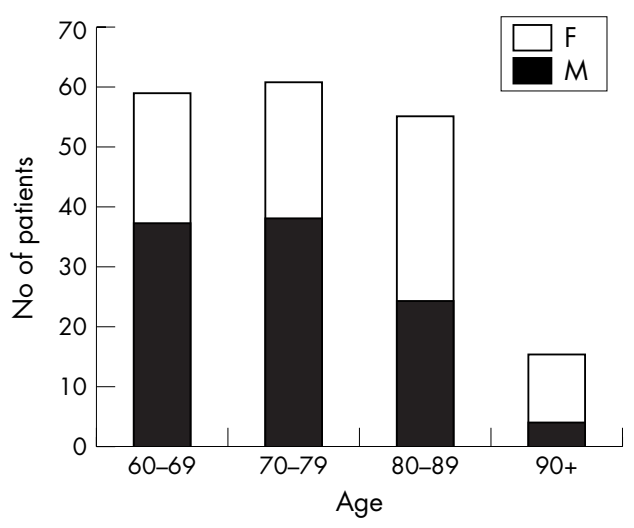

Figure 1 Patient age groups and sex distribution.

(HSV) using direct fluorescent antibody (DFA) assay, viral culture, or more recently polymerase chain reaction (PCR). ${ }^{6}$ The media were sent to the South Eastern Area Laboratory Services (SEALS) at the Prince of Wales Hospital, Randwick, NSW, for culture and antibiotic susceptibility. All bacterial isolates were identified using conventional laboratory techniques and stored at $-70^{\circ} \mathrm{C}$. The minimum inhibitory concentration (MIC) of selected antibiotics was determined on each isolate using an agar dilution technique, which conformed to the recommendations of the International Collaborative Study on Antibiotic Sensitivity Testing. ${ }^{7}$

\section{RESULTS}

Over the 4 year study period we identified 190 patients for inclusion in the study. Medical records were available for all patients. There were 103 (54\%) male and 87 (46\%) female patients, with a mean age of 75.5 (SD 9.6) years (range 60101). The age distribution is shown in figure 1 , which shows that although, overall, males are slightly over-represented, beyond the age of 80 there is a female preponderance. The peak incidence occurred in the winter months of JuneAugust, during which there were 73 (38\%) admissions (fig 2). The mean length of hospital admission was 17.6 (SD 13.1) days.

\section{Predisposing factors}

At least one local risk factor was present in 178 (93.7\%) patients (table 1), with more than one risk factor in 42 $(22.1 \%)$. Previous ocular surgery was the most prevalent risk factor, occurring in $88(46.3 \%)$ patients, but note the small numbers of patients with a history of trauma $(3.7 \%)$, or contact lens wear $(1.1 \%)$, as shown in table 1 . Systemic risk factors were identified in $53(27.9 \%)$ patients. These are summarised in table 2 .

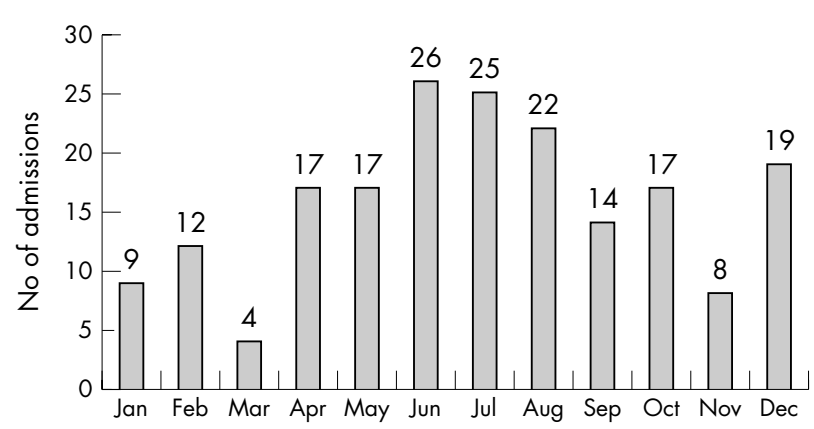

Figure 2 Seasonal variation of admissions.
Table 1 Identified pre-existing local risk factors

\begin{tabular}{|c|c|c|}
\hline Risk factor & No & $\%$ \\
\hline Previous ocular surgery & 88 & 46.3 \\
\hline Cataract surgery & 66 & 34.7 \\
\hline Pseudophakia & 62 & 32.6 \\
\hline Glaucoma & 48 & 25.3 \\
\hline Reduced corneal sensation & 38 & 20.0 \\
\hline Herpes simplex keratitis & 33 & 17.4 \\
\hline Corneal graft & 21 & 11.1 \\
\hline Bullous keratopathy & 17 & 8.9 \\
\hline Dry eye & 15 & 7.9 \\
\hline Trichiasis & 12 & 6.3 \\
\hline Aphakia & 11 & 5.8 \\
\hline Herpes zoster ophthalmicus* & 10 & 5.3 \\
\hline Rubeosis iridis & 8 & 4.2 \\
\hline Trauma & 7 & 3.7 \\
\hline Exposure & 6 & 3.2 \\
\hline Corneal scarring & 6 & 3.2 \\
\hline Topical steroid use & 4 & 2.1 \\
\hline Failed corneal graft & 4 & 2.1 \\
\hline Uveitis & 4 & 2.1 \\
\hline Recurrent erosion & 3 & 1.6 \\
\hline Loose suture/suture related & 3 & 1.6 \\
\hline Entropion & 3 & 1.6 \\
\hline Cicatrising conjunctivitis & 3 & 1.6 \\
\hline Contact lens & 2 & 1.1 \\
\hline Foreign body & $\overline{1}$ & 0.5 \\
\hline Other† & 5 & 2.6 \\
\hline Any & 178 & 93.7 \\
\hline More than 1 risk factor & 42 & 22.1 \\
\hline
\end{tabular}

*Two patients had active $\mathrm{HZO}$, the remaining eight had a previous history of $\mathrm{HZO}$.

tIncluding trachoma, corneal calcification, phthisis bulbi, scleritis, and peripheral ulcerative keratitis.

\section{Microbiology}

Corneal scrapes were taken for microbiological investigation in $172(90.5 \%)$ patients. In addition, $66(34.7 \%)$ patients were tested variously for HSV as follows: 42 (22.1\%) with PCR, 32 $(16.8 \%)$ with DFA assay, 20 (10.5\%) with viral serology, and four $(2.1 \%)$ with viral culture.

In only $25(14.5 \%)$ patients were organisms identified on the Gram stain, most of these being Gram positive cocci (16), with Gram positive bacilli in five cases, and Gram negative bacilli in five cases, and multiple types in two patients.

Organisms were cultured in $108(62.8 \%)$ of those where scrapes were taken, with more than one organism in 12 $(11.1 \%)$ of those culture positive patients. The types of organism identified are shown in table 3, and the antibiotic susceptibilities as stated in the laboratory reports, are shown in table 4. Topical antibiotics had been used before presentation in $25(39.1 \%)$ of the culture negative patients, and 41 $(38.0 \%)$ of culture positive patients.

Fifteen of the 42 patients (36\%) tested with HSV-PCR were positive. Of these 15 positive patients, nine $(60 \%)$ had no previous history of herpetic eye disease, and seven (47\%)

Table 2 Identified systemic risk factors

\begin{tabular}{lcc}
\hline Risk factor & No & $\%$ \\
\hline Diabetes & 21 & 11.1 \\
Cerebrovascular accident (CVA) & 17 & 8.9 \\
Rheumatoid arthritis & 14 & 7.4 \\
Connective tissue disease & 7 & 3.7 \\
Dementia & 7 & 3.7 \\
Myeloproliferative & 5 & 2.6 \\
Chronic alcoholism & 4 & 2.1 \\
Severe malnourishment & 2 & 1.1 \\
Brainstem tumour & 1 & 0.5 \\
At least 1 risk factor & 53 & 27.9 \\
\hline
\end{tabular}




\begin{tabular}{lrr}
\hline Table 3 Organisms cultured & \multicolumn{2}{l}{} \\
\hline Organism & No & \multicolumn{1}{c}{$\%$} \\
\hline Staphylococcus sp & 52 & 47.2 \\
Coagulase negative Staphylococcus & 30 & 27.8 \\
Staphylococcus aureus & 22 & 20.4 \\
Streptococcus sp & 13 & 12.0 \\
Strep pneumoniae & 6 & 5.6 \\
B haemolytic Streptococcus & 3 & 2.8 \\
Corynebacterium sp & 14 & 6.5 \\
Other Gram positive & 3 & 2.8 \\
Total Gram positive & 82 & 75.9 \\
Pseudomonas sp & 14 & 13.0 \\
P aeruginosa & 12 & 11.1 \\
Bacillus sp & 4 & 3.7 \\
Moraxella sp & 5 & 4.6 \\
Other Gram negative & 5 & 4.6 \\
Total Gram negative & 28 & 25.9 \\
Fungi & 4 & 3.7 \\
Nocardia sp & 2 & 1.9 \\
Acanthamoeba & 2 & 1.9 \\
More than 1 organism & 12 & 11.1 \\
Total with positive culture & 108 & \\
\hline
\end{tabular}

were culture negative for bacteria. In contrast, only one of 32 patients $(3.1 \%)$ who were tested with HSV-DFA was positive, and all four patients tested with viral culture were negative.

There were 19 patients in whom both PCR and DFA assays were performed for HSV, and of these, nine had positive HSV-PCR (47\%), but all were negative on HSV-DFA testing. Of the serological tests for HSV, 19 (95\%) of the 20 patients tested were IgG positive, indicating previous exposure, but all 20 were negative for IgM. HSV infection was suspected as a contributory factor in $43(22.6 \%)$ patients overall.

\section{Clinical features}

Consistently encountered clinical features are summarised in table 5. Perforation, descemetocele, or severe thinning occurred in $12(80.0 \%)$ of the 15 patients who were HSV PCR positive compared to $42(30.4 \%)$ of the 138 patients with purely bacterial keratitis, and $69(36.3 \%)$ patients overall.

\section{Treatment}

First line treatment in the majority of patients consisted of a standard regimen of intensive fortified topical antibiotics in the form of cephalothin $5 \%$ and gentamicin $0.9 \%$ on an alternating half hourly basis for the first 24-48 hours (table 6). This was then tapered according to clinical response. This regimen was used in $129(67.9 \%)$ patients. A further $29(15.3 \%)$ patients were given intensive topical fluoroquinolone monotherapy (either ofloxacin $0.3 \%$ or ciprofloxacin $0.3 \%$ ) on a similar basis. Antiviral therapy was used in $60(31.6 \%)$ patients.
The mean duration of topical antibiotic treatment was 3.8 (2.9) weeks (excluding postoperative prophylactic antibiotics). Initial antibiotic treatment was modified in 28 (14.7\%) patients in light of microbiology results.

Acute surgical intervention was required in 83 (43.7\%) patients (table 7 ), with acute penetrating keratoplasty (PK) performed in $34(17.9 \%)$, and $17(8.9 \%)$ requiring removal of the eye. Of the 14 patients who were culture positive for Pseudomonas sp, nine (64\%) required some surgical intervention, with loss of the eye in three $(21 \%)$, and acute PK in three $(21 \%)$ patients

\section{Complications}

Complications occurred in 93 (48.9\%) patients overall, with more than one complication in $11(5.8 \%)$. Details are summarised in table 8 .

\section{Visual outcome}

Mean presenting visual acuity was 1.82 (1.24), equivalent to $6 / 300$, excluding $50(26.3 \%)$ patients with vision of LP or worse. Mean visual acuity at last follow up was 1.24 (1.16), equivalent to 6/100, excluding $37(19.5 \%)$ patients with vision of LP or worse $(p<0.0005)$. Table 9 summarises the visual outcome among the viral and non-viral keratitis groups. There were $36(18.9 \%)$ patients with visual acuity of at least 6/12 at last follow up, compared to $13(6.8 \%)$ at presentation, and $79(41.6 \%)$ patients who had visual acuity of worse than 6/60 at last follow up. Importantly, this left 16 $(8.4 \%)$ patients legally blind because of pre-existing contralateral poor vision.

\section{DISCUSSION}

\section{Patient demographics}

The elderly make up a significant proportion of patients admitted to hospital with severe infective keratitis. We found 190 patients of 60 years and over with this diagnosis admitted to the Sydney Eye Hospital, a large tertiary referral teaching hospital, over a 4 year period. Over the same period, a total of 426 patients were admitted to our unit with this diagnosis. Those over 60 therefore constitute $45 \%$ of total admissions for infective keratitis at our unit.

Kunimoto et $\mathrm{l}^{2}$ studied 102 cases of microbial keratitis in the over $65 \mathrm{~s}$, over a 4 year period, at a tertiary referral centre in rural southern India. Their group had a mean age of 69, with a significant male preponderance $(70.6 \%)$. The setting of that study, in a rural tropical region of southern India, contrasts with our study in the temperate zone of Sydney, Australia. We found only a minimal male preponderance in our group, compared to over $70 \%$ in the study by Kunimoto, and we found, beyond the age of 80 , females were overrepresented. This may be because, in our study, 70 (36.8\%) patients were 80 years or over, compared to only six $(5.9 \%)$ patients in the study by Kunimoto. In the only previous study

Table 4 Antibiotic susceptibilities

\begin{tabular}{|c|c|c|c|c|c|c|c|c|c|c|}
\hline & \multicolumn{2}{|c|}{ Chloramphenicol } & \multicolumn{2}{|c|}{ Ciprofloxacin } & \multicolumn{2}{|c|}{ Gentamicin } & \multicolumn{2}{|l|}{ Penicillin } & \multicolumn{2}{|c|}{ Cephalothin } \\
\hline & No & $\%$ & No & $\%$ & No & $\%$ & No & $\%$ & No & $\%$ \\
\hline Staphylococcus sp & $35(41)$ & 85.4 & $25(28)$ & 89.3 & $3(7)$ & 42.9 & $13(43)$ & 30.2 & 34 (39) & 87.2 \\
\hline Staph aureus & $15(16)$ & 93.8 & $10(12)$ & 83.3 & $1(4)$ & 25.0 & $1(16)$ & 6.3 & $16(16)$ & 100.0 \\
\hline Coag negative Staphylococcus & $20(25)$ & 80.0 & $15(16)$ & 93.8 & $2(3)$ & 66.7 & $12(27)$ & 44.4 & $18(23)$ & 78.3 \\
\hline Streptococcus sp & $8(8)$ & 100.0 & $2(2)$ & 100.0 & $0(2)$ & 0.0 & $8(8)$ & 100.0 & $2(2)$ & 100.0 \\
\hline Corynebacterium & $6(8)$ & 75.0 & $6(7)$ & 85.7 & - & - & $11(12)$ & 91.7 & $6(6)$ & 100.0 \\
\hline Pseudomonas & - & - & $12(12)$ & 100.0 & $14(14)$ & 100.0 & - & - & $9(9)^{*}$ & 100.0 \\
\hline
\end{tabular}

Numbers shown are number of sensitive isolates (total tested).

*Ceftazidime.

Percentages are percentage of sensitive isolates. 
Table 5 Clinical features (numbers shown are number of patients (\%))

\begin{tabular}{|c|c|c|c|c|c|c|c|}
\hline & All patients & HSV* & HSV PCR +† & Bacterial & HSV + bacterial & Gram positive & Gram negative \\
\hline Epithelial defect & $166(87.4)$ & $27(87.1)$ & $12(80.0)$ & $119(86.2)$ & $12(100.0)$ & $65(90.3)$ & $22(78.6)$ \\
\hline Infiltrate & $132(69.5)$ & $11(35.5)$ & $7(46.7)$ & $106(76.8)$ & 7 (58.3) & $54(75.0)$ & $21(75.0)$ \\
\hline Anterior uveitis & $105(55.3)$ & $11(35.5)$ & $6(40.0)$ & $81(58.7)$ & $9(75.0)$ & 47 (65.3) & $21(67.9)$ \\
\hline Hypopyon & $55(28.9)$ & $3(9.7)$ & $1(6.7)$ & $50(36.2)$ & $2(16.7)$ & $25(34.7)$ & $13(46.4)$ \\
\hline Oedema & $46(24.2)$ & $7(22.6)$ & $4(26.7)$ & $30(21.7)$ & $5(41.7)$ & $14(19.4)$ & $7(25.0))$ \\
\hline Necrosis/thinning & $34(17.9)$ & $8(25.8)$ & $8(53.3)$ & $23(16.7)$ & $3(25.0)$ & $15(20.8)$ & $7(25.0))$ \\
\hline Perforation & $23(12.1)$ & $9(29.0)$ & $3(20.0)$ & $13(9.4)$ & $1(8.3)$ & $7(9.7)$ & $2(7.1)$ \\
\hline Descemetocele & $12(6.3)$ & $5(16.1)$ & $1(6.7)$ & $6(4.3)$ & $1(8.3)$ & $3(4.2)$ & $0(0.0)$ \\
\hline Vascularisation & $21(11.1)$ & $6(19.4)$ & $4(26.7)$ & $11(8.0)$ & $3(25.0)$ & $8(11.1)$ & $3(10.7)$ \\
\hline Raised IOP & $7(3.7)$ & $2(6.5)$ & $1(6.7)$ & $5(3.6)$ & $0(0.0)$ & $3(4.2)$ & $1(3.6)$ \\
\hline Total & 190 & 31 & 15 & 138 & 12 & 72 & 28 \\
\hline
\end{tabular}

*Clinical or laboratory diagnosed cases of HSV keratitis.

TPCR positive cases of HSV keratitis.

of microbial keratitis in the elderly from a temperate region, Ormerod $^{1}$ studied only bacterial keratitis in 142 patients aged 65 years and over, between 1977 and 1984 at several centres in Boston and Los Angeles, United States. He found an equal sex distribution.

\section{Predisposing factors}

The vast majority (94\%) of our patients had at least one identifiable risk factor. This is in common with previous age independent studies where risk factors were identified in 88$91 \%^{4-10}$ although the overall proportion of patients with identifiable risk factors is not stated in the studies by Ormerod $^{1}$ or Kunimoto et $\mathrm{al}^{2}$ in the elderly.

However, in older patients the types of risk factors differ from younger age groups. Contact lens wear and trauma, common among younger groups, ${ }^{489}$ were uncommon in our series, but previous ocular disease and surgery accounted for the majority. This compares with Ormerod's findings, where the leading risk factors were: use of topical corticosteroids $(38 \%)$, corneal scarring (33\%), contact lens wear $(25 \%)$, and bullous keratopathy (19\%). ${ }^{1}$ Much less frequent were trauma $(5 \%)$, and "recent" cataract surgery $(4 \%)$, although the number who had undergone previous ocular surgery is not stated. The use of contact lenses among the elderly has declined since the study by Ormerod from 25 years ago, with the advent of more modern cataract surgery techniques, and far fewer aphakic patients. Kunimoto et al found previous ocular disease (35\%), and previous ocular surgery (29\%) to be the main risk factors, very few contact lens wearers $(2 \%)$ as

Table 6 Topical and systemic treatment used

\begin{tabular}{lrr}
\hline & No & $\%$ \\
\hline Topical treatment & & \\
Cephalothin and gentamicin & 129 & 67.9 \\
Fluoroquinolone & 29 & 15.3 \\
Chloramphenicol & 25 & 13.2 \\
Antiviral & 60 & 31.6 \\
$\quad$ Antiviral (topical) & 47 & 24.7 \\
$\quad$ Antiviral (systemic) & 42 & 22.1 \\
Antifungal & 3 & 1.6 \\
Antiamoebic agent & 2 & 1.1 \\
Other topical treatment & 125 & 65.8 \\
Mydriatic & 67 & 35.3 \\
Steroid & 47 & 24.7 \\
Hypotensive & 35 & 18.4 \\
Lubricants & & \\
Systemic treatment & 42 & 22.1 \\
Antiviral & 28 & 14.7 \\
Antibiotics & 13 & 6.8 \\
Doxycycline & 11 & 5.8 \\
Steroid & 7 & 3.7 \\
Multivitamins &
\end{tabular}

in our study, but found a high rate of trauma (18\%) among their group from rural India. ${ }^{2}$

Unsurprisingly, systemic risk factors are also more common in the elderly, present in $28 \%$ of our cases. Ormerod ${ }^{1}$ found $28 \%$ with systemic risk factors, compared to $17 \%$ among the group of Kunimoto et al. ${ }^{2}$ In contrast, Bourcier et $a l^{9}$ found systemic predisposing factors in only $5.8 \%$ in their series of 291 patients with a mean age of 39 .

These represent only those risk factors that are readily definable and measurable. Other factors such as mobility, access to health care, support network, socioeconomic factors, dexterity, and compliance will undoubtedly have an important impact on the older patient, and therefore their susceptibility to disease and response to treatment. These are much less easily assessed, and the risk factors stated in this study, are therefore probably an underestimate in the overall context of these patients' disease.

\section{Microbiology}

Our culture positive rate of $63 \%$ is similar to previous reports, $^{3-13}$ and $76 \%$ of cultured organisms were Gram positive in our series. In this study, we found that the microbiological spectrum is similar to recent age independent series from temperate regions of the world..$^{8111314}$ It is interesting that the common pathogens of the outer eye have remained relatively constant for decades, with similar results reported by Musch et al, ${ }^{4}$ and Ormerod $^{1} 25$ years ago. The latter found $66 \%$ were Gram positive, with the leading organisms being coagulase negative staphylococci $(23 \%)$, Staphylococcus aureus (23\%), Streptococcus pneumoniae (14\%), and Pseudomonas aeruginosa (20\%). Goldstein et al ${ }^{14}$ reported a decrease in the proportion of Gram positive bacterial keratitis over the past decade, and postulated that the rise in the empirical use of fluoroquinolones in the community, may have had an effect on culture rates and patterns. However, in a similar study, Alexandrakis et al ${ }^{12}$ found no such trend.

HSV was implicated in $43(22.6 \%)$ patients. In 15 patients (7.9\%) PCR for HSV was positive, suggesting active infection. Interestingly, $60 \%$ of these had no previous history of herpetic eye disease, and in half, HSV was the only organism identified. PCR has previously been shown to be a sensitive method for the detection of HSV in keratitis. ${ }^{15-17}$ Although the numbers are small in this series, it would seem that PCR has a higher detection rate for HSV than DFA assay. Of the 19 tested by both methods, nine (47\%) were positive on PCR, but all were negative on DFA assay.

Previous studies in the elderly have excluded HSV keratitis. ${ }^{12}$ Our series shows significant morbidity associated with HSV in the elderly, either as a predisposing factor, in polymicrobial infection, or as the single causative pathogen. Previous age independent series of microbial keratitis have tended to focus on bacterial causes, but rates of $1.8-2.0 \%$ for 
Table 7 Acute surgical interventions (numbers shown are number of patients (\%))

\begin{tabular}{|c|c|c|c|c|}
\hline & All patients & Viral & Mixed* & Non-viral \\
\hline Penetrating keratoplasty & $34(17.9)$ & $8(25.8)$ & $2(16.7)$ & $24(16.3)$ \\
\hline Tarsorrhaphy & 26 (13.7) & 4 (12.9) & $0(0.0)$ & $22(15.0)$ \\
\hline Evisceration/enucleation & $17(9.0)$ & $1(3.2)$ & $0(0.0)$ & $16(10.9)$ \\
\hline Corneal glue & $9(4.7)$ & $7(22.6)$ & $0(0.0)$ & $2(1.4)$ \\
\hline Conjunctival flap & $5(2.6)$ & $0(0.0)$ & $1(8.3)$ & $4(2.7)$ \\
\hline Amniotic membrane graft & $3(1.6)$ & $0(0.0)$ & $0(0.0)$ & $3(2.0)$ \\
\hline Lamellar keratoplasty & $2(1.1)$ & $0(0.0)$ & $0(0.0)$ & $2(1.4)$ \\
\hline Botulinum toxin ptosis & $2(1.1)$ & $0(0.0)$ & $0(0.0)$ & $2(1.4)$ \\
\hline None & $107(56.3)$ & $12(38.7)$ & $9(75.0)$ & $86(58.5)$ \\
\hline Any & $83(43.7)$ & $19(61.3)$ & $3(25.0)$ & $61(41.5)$ \\
\hline Total & 190 & 31 & 12 & 147 \\
\hline
\end{tabular}

HSV have been reported. ${ }^{8}{ }^{18}$ It might be expected that as immunity reduces with age, the impact of herpetic eye disease may increase. Certainly a high index of suspicion for HSV as a contributor or cause of keratitis must be maintained in the elderly.

\section{Treatment}

All the main bacterial species were sensitive to at least one of the most commonly used antibiotics, although the numbers were small among some of the groups tested. In particular, we found no resistance of Pseudomonas to ciprofloxacin, gentamicin, or ceftazidime among those tested. Hyndiuk et $a l^{11}$ have shown fluoroquinolone monotherapy to be clinically and statistically equivalent to standard dual fortified antibiotic therapy in bacterial keratitis in a randomised, double masked, multi centre trial. However, there have been several reports showing increasing resistance to fluoroquinolones, particularly among Streptococcus sp, ${ }^{10} 1419$ coagulase negative staphylococci, ${ }^{10}{ }^{12}{ }^{19}$ and Pseudomonas sp. ${ }^{20}$ We found some resistance to ciprofloxacin among the staphylococci isolated, but the majority remained sensitive. In a retrospective review of 138 cases, Gangopadhyay et al ${ }^{13}$ reported an increased incidence of corneal perforation among those treated with fluoroquinolone monotherapy compared to standard dual fortified antibiotic therapy, and cautioned the use of fluoroquinolone monotherapy in severe keratitis, particularly in the elderly.

Our data support the initial empirical use of intensive fortified cephalosporin and gentamicin as first line therapy in the elderly, which the majority of our patients received. Fluoroquinolone monotherapy should perhaps not be first choice, given the resistance among some staphylococci, which was the most frequently identified organism in our series, although in vitro resistance does not necessitate lack of clinical response.

The high surgical intervention rate of $43.7 \%$ in our series is higher than reported by Ormerod (29\%), ${ }^{1}$ although similar to Kunimoto et al (41.2\%). ${ }^{2}$ These rates from series among the elderly are much higher than in age independent series where rates of $1.3-21.4 \%^{8}{ }^{18}$ are reported. It is likely that delayed presentation, poor nutrition or hydration, reduced immunity, co-existent disease, and poor healing contribute to the higher rate among the elderly.

\section{Complications}

Almost half the patients in our series had at least one complication. There was a high rate of perforation (12.1\%), and this is reflected in the high rates of acute keratoplasty and removal of the eye. Interestingly, perforation or severe thinning occurred in $30 \%$ overall, but in over $70 \%$ of those with positive HSV PCR. This diagnosis should therefore be suspected in those who develop threatened or actual perforation. Previous series in the elderly have reported high rates of enucleation/evisceration $\left(7 \%^{1}\right.$ and $\left.14.7 \%^{2}\right)$, which compares to our rate of $8.9 \%$, whereas age independent series report rates of less than $1 \% .^{89}$

\section{Visual outcome}

Previous studies of infective keratitis in the elderly have not commented on presenting visual acuity. ${ }^{12}$ The patients in this series had a very poor presenting mean visual acuity (6/300), excluding over $25 \%$ having LP or worse. This is unlike younger patients: Wong et $a l^{8}$ reported mean presenting visual acuity of 0.86 (equivalent to 6/36-6/48), and Bourcier et $a l^{9}$ reported $0.51(6 / 18-6 / 24)$. Our study also highlights the poor visual outcome of infective keratitis among the elderly, with over $40 \%$ worse than $6 / 60$, and almost $20 \%$ LP or worse at last follow up. Kunimoto et $a^{2}$ also found a poor outcome among the elderly with $75 \%$ worse than $20 / 400$. Younger patients do much better, with Wong et al reporting a mean final visual acuity of $0.36(6 / 12-6 / 15)$.

\section{CONCLUSIONS}

The present study is limited by its retrospective design, the lack of a younger control group, and the heterogeneity of this difficult patient group who have multiple associated factors. It is also based on patients who were admitted to hospital, as is frequently necessary in older patients, but this will select

Table 8 Complications (numbers shown are number of patients (\%))

\begin{tabular}{lcclc}
\hline & All patients & Viral & Mixed* & Non-viral \\
\hline Scarring (visually significant) & $47(24.7)$ & $6(19.4)$ & $3(25.0)$ & $38(25.9)$ \\
Persistent epithelial defect & $25(13.2)$ & $5(16.1)$ & $0(0.0)$ & $20(13.6)$ \\
Perforation & $23(12.1)$ & $10(32.3)$ & $1(8.3)$ & $12(8.2)$ \\
Loss of eye & $17(8.9)$ & $1(3.2)$ & $0(0.0)$ & $16(10.9)$ \\
Raised IOP/glaucoma & $6(3.2)$ & $2(6.5)$ & $0(0.0)$ & $4(2.7)$ \\
Cataract & $4(2.1)$ & $0(0.0)$ & $0(0.0)$ & $4(2.7)$ \\
Other & $4(2.1)$ & $3(9.7)$ & $1(8.3)$ & $0(0.0)$ \\
Any complication & $93(48.9)$ & $24(77.4)$ & $5(41.7)$ & $64(43.5)$ \\
More than 1 complication & $11(5.8)$ & $2(6.5)$ & $0(0.0)$ & $9(6.1)$ \\
\hline *Mixed viral and bacterial keratitis. & & &
\end{tabular}


Table 9 Visual outcome among viral and non-viral patient groups

\begin{tabular}{|c|c|c|c|c|c|c|c|}
\hline & \multirow{2}{*}{$\begin{array}{l}\text { Mean preop visual } \\
\text { acuity }^{*}\end{array}$} & \multirow[b]{2}{*}{ SD } & \multirow{2}{*}{$\begin{array}{l}\text { Mean postop visual } \\
\text { acuity* }^{*}\end{array}$} & \multirow[b]{2}{*}{ SD } & \multirow[b]{2}{*}{ p Value } & \multicolumn{2}{|c|}{ LP or worse† (\%) } \\
\hline & & & & & & Presentation & Last visit \\
\hline All patients & $1.82(6 / 300)$ & 1.24 & $1.24(6 / 100)$ & 1.16 & $<0.0005$ & $50(26.3)$ & 37 (19.5) \\
\hline Viral & $2.12(6 / 600)$ & 1.15 & $1.56(6 / 200)$ & 1.28 & 0.01 & $4(9.3)$ & $3(7.0)$ \\
\hline Non-viral & $1.69(6 / 300)$ & 1.26 & $1.13(6 / 86)$ & 1.11 & $<0.0001$ & 46 (31.3) & $34(23.1)$ \\
\hline
\end{tabular}

for patients with more severe disease. However, this study confirms the elderly represent a distinct clinical group in the context of microbial keratitis. Predisposing factors are very common, they present with poor vision, had a high complication and surgical intervention rate, and a poor visual outcome compared to younger patient groups. The microbiological spectrum is similar to that seen in the younger population, except that HSV is more common and may increase the risk of severe corneal thinning and perforation. Most bacterial isolates remain sensitive to currently available antibiotic preparations.

\section{ACKNOWLEDGEMENTS}

We acknowledge the support of the Sydney Eye Hospital Foundation, and the Save Sight Institute, University of Sydney.

\section{Authors' affiliations}

T K H Butler, N A Spencer, C C K Chan, J S Gilhotra, K McClellan, Department of Clinical Ophthalmology and Save Sight Institute, University of Sydney, GPO Box 4337, Sydney, NSW, 2001, Australia

Competing interests: none declared

\section{REFERENCES}

1 Ormerod LD. Causes and management of bacterial keratitis in the elderly. Can J Ophthalmol 1989;24:112-16.

2 Kunimoto DY, Sharma S, Garg P, et al. Corneal ulceration in the elderly in Hyderabad, south India. Br J Ophthalmol 2000;84:54-9.

3 Morlet N, Minassian D, Butcher J, The Ofloxacin Study Group. Risk factors for treatment outcome of suspected microbial keratitis. Br J Ophthalmol 1999;83:1027-31.

4 Musch DC, Sugar A, Meyer RF. Demographic and predisposing factors in corneal ulceration. Arch Ophthalmol 1983;101:1545-8.

5 Holladay JT. Proper method for calculating average visual acuity. J Refract Surg 1997;13:388-91.
6 Read SJ, Kurtz JB. Laboratory diagnosis of common viral infections of the CNS by using a single multiplex PCR screening assay. J Clin Microbiol 1999;37:1352-5

7 Ericsson HM, Sherris JC. Antibiotic sensitivity testing. Report of an international collaborative study. Acta Pathol Microbiol Scand 1971;(Suppl 217): 1-90.

8 Wong T, Ormonde S, Gamble G, et al. Severe infective keratitis leading to hospital admission in New Zealand. Br J Ophthalmol 2003;87:1 103-8.

9 Bourcier T, Thomas F, Borderie $\mathrm{V}$, et al. Bacterial keratitis: predisposing factors, clinical and microbiological review of 300 cases. Br J Ophthalmol 2003;87:834-8.

10 Schaefer F, Bruttin O, Zografos L, et al. Bacterial keratitis: a prospective clinical and microbiological study. Br J Ophthalmol 2001;85:842-7.

11 Hyndiuk RA, Eiferman RA, Caldwell DR, et al. Comparison of ciprofloxacin ophthalmic solution $0.3 \%$ to fortified tobramycin-cefazolin in treating bacterial corneal ulcers. Ciprofloxacin Bacterial Keratitis Study Group. Ophthalmology 1996; 103:1854-62.

12 Alexandrakis G, Alfonso EC, Miller D. Shifting trends in bacterial keratitis in south Florida and emerging resistance to fluoroquinolones. Ophthalmology 2000;107:1497-502.

13 Gangopadhyay N, Daniell M, Weih L, et al. Fluoroquinolone and fortified antibiotics for treating bacterial corneal ulcers. Br J Ophthalmol 2000;84:378-84.

14 Goldstein MH, Kowalski RP, Gordon YJ. Emerging fluoroquinolone resistance in bacterial keratitis: a 5-year review. Ophthalmology 1999:106:1313-18.

15 Yamamoto S, Shimomura Y, Kinoshita S, et al. Detection of herpes simplex virus DNA in human tear film by the polymerase chain reaction. Am J Ophthalmol 1994;117:160-3.

16 Tei M, Nishida K, Kinoshita S. Polymerase chain reaction detection of herpes simplex virus in tear fluid from atypical herpetic epithelial keratitis after penetrating keratoplasty. Am J Ophthalmol 1996;122:732-5.

17 Koizumi N, Nishida K, Adachi W, et al. Detection of herpes simplex virus DNA in atypical epithelial keratitis using polymerase chain reaction. Br J Ophthalmol 1999;83:957-60.

18 Gebaver A, McGhee CN, Crawford GJ. Severe microbial keratitis in temperate and tropical Western Australia. Eye 1996;10:575-80.

19 Kunimoto DY, Sharma S, Garg P, et al. In vitro susceptibility of bacterial keratitis pathogens to ciprofloxacin. Ophthalmology 1999;106:80-5.

20 Song A, McCulley TJ, Lam BL, et al. Pseudomonas aeruginosa in vitro corneal isolate sensitivity to ofloxacin, ciprofloxacin, and trovafloxacin: a comparative study. Am J Ophthalmol 2001;131:795-6. 